\title{
Effect of Elastase-induced Emphysema on the' Force-generating Ability of the Diaphragm
}

\author{
Gerald S. Supinski and Steven G. Kelsen, Pulmonary Division, Department of \\ Medicine, Case Western Reserve University, Cleveland, Ohio 44106
}

A B S T R A C T The effect of emphysema on the ability of the diaphragm to generate force was examined in costal diaphragm muscle strips from 10 Golden hamsters killed 18 mo after intratracheal injection of pancreatic elastase in a dose producing hyperinflation (mean total lung capacity $[$ TLC] $=163 \%$ of control) and generalized panacinar emphysema. 13 saline-injected normal animals served as controls. The time course of isometric tension and the effect of alterations in muscle fiber and sarcomere length on the isometric tension $(T)$ generated in response to tetanizing electrical stimuli (length-tension [L-T] relationship) were examined. Elastase administration caused an increase in diaphragm muscle thickness and reduction in the length of costal diaphragm muscle fibers measured in situ. Emphysema significantly increased the maximum tetanic tension as a result of hypertrophy. Maximal tension corrected for increases in muscle cross-sectional area $\left(\mathrm{T} / \mathrm{cm}^{2}\right)$, however, was the same in emphysematous (E) and control (C) animals. Emphysema also shifted the muscle fiber L-T curve of the diaphragm but not of a control muscle, the soleus, toward shorter lengths. In contrast to the effects of $E$ on the diaphragm muscle fiber L-T curve, the sarcomere L-T curve was the same in $E$ and $C$. Since the length at which tension was maximal correlated closely with sarcomere number $(r=0.94 ; P<0.001)$ reduction in the number of sarcomeres in series in muscles from emphysematous animals appeared to explain the shift in the muscle fiber L-T curve. We conclude that in elastase-induced emphysema adaptive changes both in diaphragm cross-sectional area and sarcomere number augment the force-generating ability of the diaphragm. We speculate that changes in sarcomere number compensate for alterations in muscle fiber length

Address correspondence to Dr. S. G. Kelsen, Department of Medicine, University Hospitals, Cleveland, $\mathrm{OH} 44106$.

Received for publication 31 March 1982 and revised form 12 July 1982. resulting from chronic hyperinflation of the thorax, while diaphragmatic muscle hypertrophy represents a response to changes in respiratory load and/or diaphragm configuration (LaPlace relationship).

\section{INTRODUCTION}

The increased airway resistance and expanded lung volume caused by emphysema increase the load on the diaphragm and alter its length and configuration (17). Acute increases in lung volume have been shown to reduce the length and hence the tension- and pressure-generating ability of the diaphragm (the lengthtension relationship of skeletal muscle (8-11). Present thinking assumes that the persistent hyperinflation associated with emphysema also places the diaphragm at a mechanical disadvantage (3-7).

In man, the need to be noninvasive has limited study of respiratory muscle function to the use of indirect indices of muscle force and length, i.e., airway pressure and lung volume, although the relationship between pressure-volume measurements and muscle length-tension is complex $(4,5,7,13,14)$. The forcegenerating ability of the diaphragm in emphysematous subjects has not been measured directly and as a result the effect of emphysema on diaphragm function remains unclear $(6,7,13)$.

In this study, we have made use of a well-characterized animal model of human emphysema, induced by intratracheal administration of elastase (15-20), to examine directly the effect of emphysema on diaphragmatic muscle function. Studies were performed in vitro using muscle strips from the costal portion of the diaphragm. Because the force generated by skeletal muscle depends on sarcomere rather than muscle length $(21,22)$, we have used laser diffraction techniques to characterize the relationship of contractile force to sarcomere as well as muscle fiber length (2328). The tension developed by a nonrespiratory muscle, the soleus, was used as a control for any direct effects of elastase administration on muscle function. 


\section{METHODS}

Studies were performed in 10 Syrian Golden hamsters (Charles River Breeding Laboratories, Wilmington, MA) in whom severe panacinar emphysema was induced by elastase administration (ICN Nutritional Biochemicals, Cleveland, $\mathrm{OH})$. Injection of porcine pancreatic elastase $(25 \mathrm{U} / 100 \mathrm{~g}$ body wt in saline) was performed under general anesthesia induced with thiopental. After the cervical trachea has been exposed via a midline incision in the neck, the airway was penetrated under direct vision with a 26-gauge needle and elastase $\left(0.3 \mathrm{~cm}^{3}\right.$ total volume $)$ instilled using a $1-\mathrm{ml}$ syringe. 13 age-matched saline-injected animals served as controls. Animals were given food and water ad lib. until killed by decapitation 18 mo after injection.

Immediately after killing, the animal was placed in the supine position, and the ventral surface of the diaphragm exposed through an abdominal incision. Using a flexible plastic grid, the fiber length of the lateral costal region of the diaphragm was measured in situ at the sites of insertion of the phrenic nerves.

The diaphragm and lower ribs were then removed en bloc and placed in oxygenated Krebs-Henselheit solution at room temperature $\left(21-23^{\circ} \mathrm{C}\right)$ for further dissection as described $(29,30)$. Using a stereoscopic microscope (Wild-Heerbrugg, model M-8, Geneva, Switzerland), $\sim 4-\mathrm{mm}$ wide, rectangular strips of the costal portion of the diaphragm surrounding the sites of insertion of right and left phrenic nerve were dissected out. The muscles' origins on the ribs and insertions in the central tendon were left intact and great care was taken to avoid damaging individual fibers.

Strips were mounted vertically in a rectangular organ bath whose anterior and posterior walls were of $1-\mathrm{mm}$ thick glass and which was filled with aerated $\left(95 \% \mathrm{O}_{2}-5 \% \mathrm{CO}_{2}\right)$ KrebsHenselheit solution (Fig. 1). The muscle strip was secured at the ribs and central tendon by fine stainless steel hooks. The hooks securing the central tendon were embedded in a plexiglass rod connected in turn to an isometric force-displacement transducer. A swivel adapter on the superior hooks allowed the plexiglass rod to be manually rotated through an arc of $360^{\circ}$. Muscle strips were often remounted and the swival adapter adjusted several times until the strip was positioned in a precisely rectangular configuration perpendicular to the laser.

Muscle fiber length was measured directly using a grad- uated plexiglass grid in close proximity to the muscle. The length of the muscle was altered using a rack and pinion gear that raised and lowered the force transducer. Supramaximal electrical stimuli (1.2-1.3 times the voltage needed to elicit maximal tension) were delivered in 0.2 -ms pulses via stainless steel electrodes in the bath (stimulator model S88, Grass Instruments Co., Quincy, MA). The isometric force generated was measured by the force transducer (model FTO3, Grass Instruments Co.).

A soleus muscle was obtained from each control and emphysematous animal, with its origin and insertion intact, and placed in an apparatus similar to that used for the diaphragm.

Mean sarcomere length of each diaphragm muscle strip was measured at each fiber length by laser diffraction (2328). This technique has been shown to accurately measure sarcomere length statically at rest and dynamically during contraction in whole muscles $(24,28)$, muscle bundles (23$25)$, and single fibers $(23,26,28)$. The technique depends on differences in the absorbance of light by the alternating dark (A) and light (I) bands of striated muscle. Each I band, thus, acts as a point source of light causing the muscle to act like a multilayered, one-dimensional transmission grating that splits a parallel beam of coherent, collimated light into a series of diffracted rays.

Mean sarcomere length (SL) - the distance between I bands-can be calculated, therefore, from the diffraction equation

$$
\mathrm{SL}=\frac{\eta \lambda}{\sin \theta}
$$

where $\lambda=$ the wavelength of light incident on the muscle, $\eta=$ the diffraction order (i.e., 0,1 st, 2 nd, et cetera) and $\theta$ equals the angle transcribed between the muscle and the respective diffraction band (Fig. 1 ).

The angle, $\theta$, in turn, can be measured by dividing the spatial separation (d) between the peak intensities of the 0 and the first order diffraction pattern by the distance (D) between the muscle and the point at which the diffraction pattern is measured (i.e., $\tan \theta$ ). Eq. 1 then becomes:

$$
\mathrm{SL}=\frac{\lambda \eta}{\sin \left(\arctan \frac{\mathrm{d}}{\mathrm{D}}\right)} .
$$

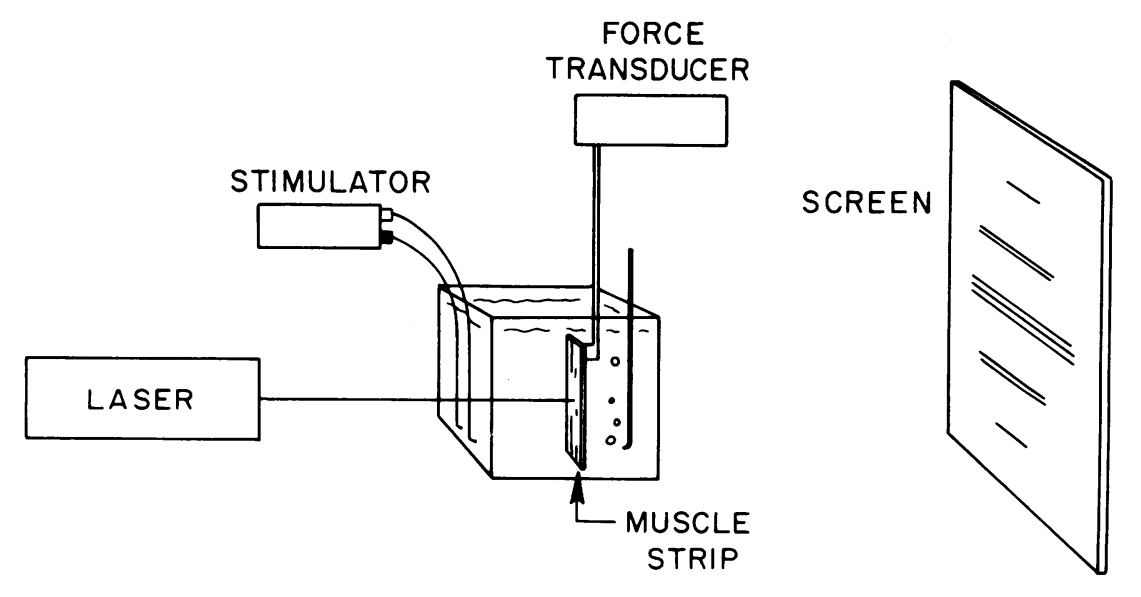

Figure 1 Schematic representation of experimental apparatus. 
In this study, coherent, monochromatic light $(\lambda=0.6328$ $\mu \mathrm{m}$; beam width $=1 \mathrm{~mm}$ ) was generated by a helium-neon laser (model 155, Spectra-Physics, Inc., Mountain View, CA) and the diffraction pattern created was projected onto a screen positioned a known distance behind the organ bath. The spatial length (d) between the peak intensities of the 0 and lst order bands (Fig. 2) was measured by eye using calipers having an accuracy of $\pm 0.5 \mathrm{~mm}$.

A series of preliminary experiments were performed to examine the validity of sarcomere values. Calibration of the system with a series of commercially available diffraction gratings $(1.9,2.5,3.3$, and $4.2 \mu \mathrm{m}$; Diff raction Projects, Inc., Woodstock, IL) substituted in the bath in place of the muscle yielded values within $\pm 2 \%$ of the manufacturer's stated values.

In preliminary experiments using the hamster diaphragm, it was observed that when the muscle was suspended in such a way that obvious variations in fiber length occurred from one region to another, sarcomere length measurement depended on the region examined. Comparison of sarcomere values obtained from different regions of the muscle using the method of suspending the muscle described above, how- ever, yielded values that varied by $<5 \%$ between regions. These findings are in agreement with previous studies in other mammalian muscles whose fibers are aligned in parallel and are of approximately equal length (24).

Finally, the number of the sarcomeres in series in tissue strips sonically disrupted into single fibers (31) was measured microscopically and results compared to those obtained by laser diffraction. Since the sarcomere number in a fiber is constant, agreement in measurements of sarcomere number between the two methods would support the accuracy of size measured by laser diffraction technique. In the laser method, sarcomere number was determined by dividing fiber length by mean sarcomere length. In the microscopic method, the number of sarcomeres per $200 \mu \mathrm{m}$ length of fiber was counted using an eyepiece micrometer (American Optical Corp., Buffalo, NY). In agreement with previous studies performed in whole limb muscles in rats and mice, sarcomere number determined by both methods agreed to w.ithin $\pm 5 \%$ (24).

Experimental protocol. After allowing strips to thermally equilibrate in the experimental apparatus for $15 \mathrm{~min}$, the muscle fiber and sarcomere length-tension curves of the dia-

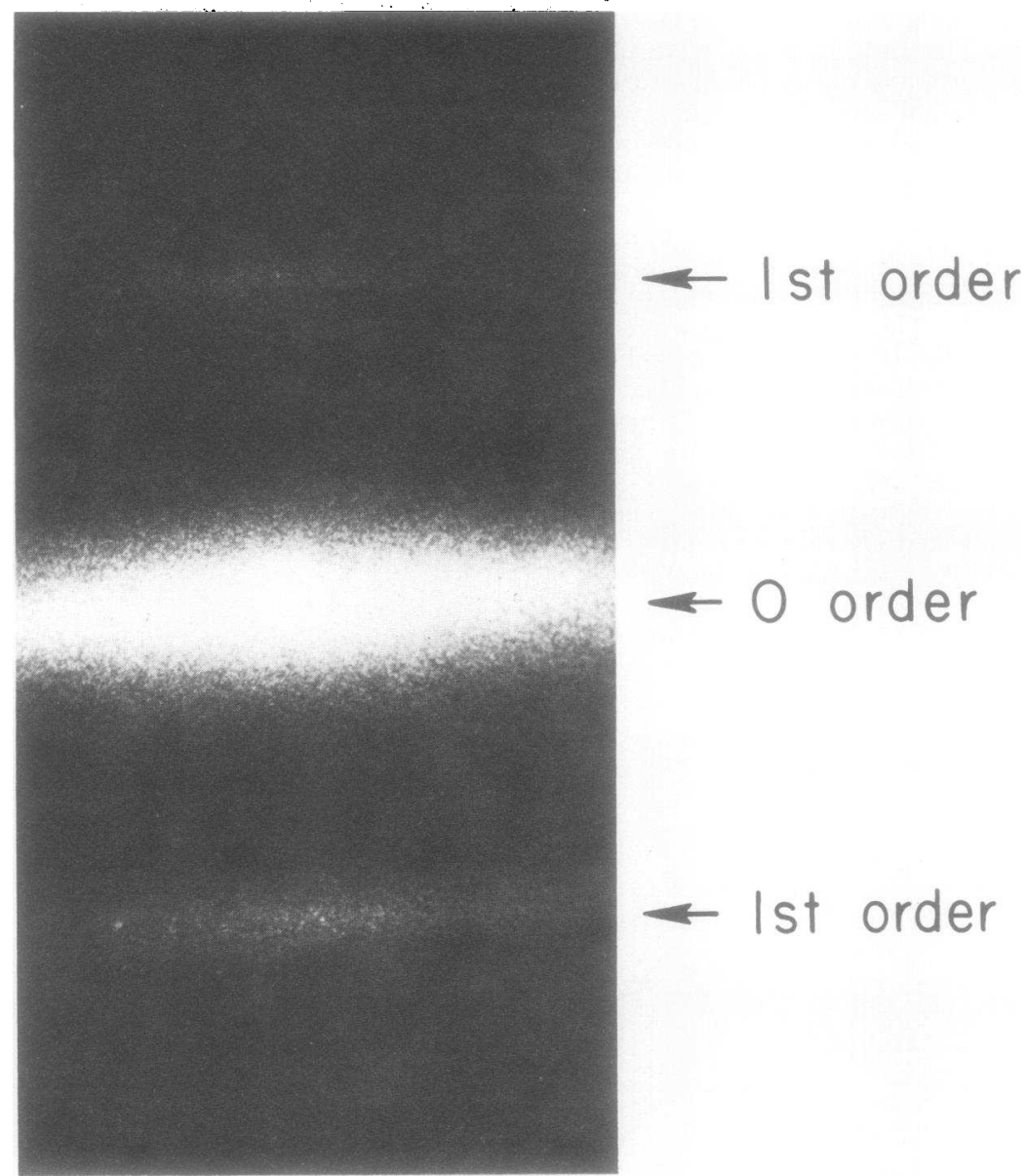

FIGURE 2 Photograph of a diffraction pattern generated by hamster diaphragmatic muscle strip exposed to helium-neon laser weight (wavelength $=0.632 \mu \mathrm{m}$ ). Sarcomere length was calculated by introducing measurements of the distance (d) between the peak intensity of the zero and lst order band into equation: sarcomere length $=\eta \lambda / \sin (\arctan d / D)$. 
TABLE I

Anthropomorphic Data

\begin{tabular}{lccccc}
\hline & Body weight & Nose-tail length & Lung volume & $\begin{array}{c}\text { Costal muscle fiber } \\
\text { length in situ }\end{array}$ & $\begin{array}{c}\text { Thickness } \\
\text { costal muscle }\end{array}$ \\
\hline & $g$ & $c m$ & $m l$ & & $m m$ \\
$\begin{array}{c}\text { Control } \\
\text { (mean } \pm 1 \text { SE) }\end{array}$ & $144.2 \pm 1.6$ & $18.9 \pm 0.4$ & $6.8 \pm 0.5$ & $15.4 \pm 0.4$ & $0.62 \pm 0.13$ \\
$\begin{array}{c}\text { Elastase } \\
\text { (mean } \pm 1 \text { SE) }\end{array}$ & $135.3 \pm 1.8$ & $18.6 \pm 0.4$ & $11.0 \pm 1.1$ & $12.8 \pm 0.5$ & $0.77 \pm 0.11$ \\
& NS & NS & $P<0.002$ & $P<0.001$ & $P<0.01$ \\
\hline
\end{tabular}

phragm were determined. At each position of the rack and pinion gear, muscle fiber length and sarcomere length were measured after which the muscle was stimulated at a frequency of $50 \mathrm{~Hz}$ for 1-2 s until tension was observed to plateau. Measurements were made of both active and passive tension (defined as the base-line tension developed by the unstimulated muscle). A 2-min period was allowed between contractions. To avoid damage to the muscle due to overextension, muscle length was only varied over a range of $\sim 75-115 \%$ of the length at which tension was maximal $\left(\mathrm{L}_{0}\right)^{1}$. Two to three sarcomere and muscle length-tension curves were obtained for each strip. The muscle strip was then returned to $L_{0}$ and the time course of the tension wave form of five to seven single twitches each at 5-s intervals was recorded on a dual beam storage oscilloscope (model 5114, Teletronix, North Hollywood, CA) and photographed for analysis of contraction and relaxation times. Contraction time (CT) was taken as the time from onset to the peak twitch tension. The rate of relaxation was assessed by the time required for tension to fall by half ( $1 / 2 \mathrm{RT})$.

To ensure that the muscle had not deteriorated during the course of the experiment, muscles were returned to $\mathrm{L}_{0}$ at the conclusion of the experiment and tension compared to previous values. In the three experiments in which tension at $\mathrm{L}_{0}$ was different, the data obtained from that strip was not used. The muscle was blotted, weighed, and then quick frozen in 2-methylbutane cooled to the temperature of liquid nitrogen. A similar protocol was used for the soleus muscle with the exception that sarcomere length was not measured.

Since the tension developed by $\alpha$ contracting muscle depends on its bulk (i.e., cross-sectional area) as well as its intrinsic force-generating ability, and since emphysema may alter both, data are expressed both in terms of the absolute tension developed by the tissue and the tension per unit cross-sectional area. Cross-sectional area was calculated as previously described by dividing the mass of the blotted tissue (weight) by the length at which tension was maximum $\left(L_{0}\right)$ (32). To independently determine if emphysema altered diaphragm bulk, the thickness of quick frozen diaphragm strips was measured. Thickness of magnified $(\times 100)$ crosssections of muscle stained for the oxidative enzyme NADHreductase, to allow better visualization, was measured using a graticule in the microscope eyepiece (33).

In each normal and emphysematous animal, the volume of excised lungs at total lung capacity was measured at the

${ }^{1}$ Abbreviations used in this paper: FRC, functional residual capacity; $L_{0}$ muscle fiber length at which tension is maximal. time of killings by water displacement during inflation with formalin ( $25 \mathrm{cmH}_{2} \mathrm{O}$ pressure).

Statistical significance of results was examined by the independent $t$ test. Correlation coefficients for the relationship between two variables was obtained by linear regression analysis.

\section{RESULTS}

Body, lung, and diaphragm muscle dimensions in emphysematous and control animals are given in Table I. Body weight and nose-to-tail length were not significantly different in emphysematous and control animals. In elastase-injected animals, the inflated lung demonstrated obvious generalized panacinar emphysema and hyperinflation (Fig. 3). Total lung capacity in emphysematous animals was $162 \%$ of control $(P$ $<0.002$ ). Muscle fiber length of the costal region measured in situ was significantly shorter in elastase-injected animals (mean $82 \%$ of control; $P<0.001$ ), while muscle thickness was significantly greater (mean $125 \%$ of control; $P<0.01$ ) (Table I).

Effects of elastase-induced emphysema on diaphragmatic tension. The time course of the tension wave form in emphysematous and control animals as assessed from the contraction time, $1 / 2$ relaxation time, and twitch-tetanus ratio is shown in Table II. Mean contraction time was 69.6 and $73.7 \mathrm{~ms}$ in control and emphysematous animals; mean $1 / 2$ relaxation time was 72.8 and $64.3 \mathrm{~ms}$, respectively $(P<0.05)$. Mean twitchtetanus ratio was 28 and $35 \%$ in control and emphysematous animals. Except for a small difference in the rate of relaxation, the time course of the tension wave forms were not different in the two groups.

The maximum force generated by the diaphragm was significantly greater in emphysematous animals. Tetanic tension at $\mathrm{L}_{0}$ was $25.9 \pm 2.4 \mathrm{~g} \mathrm{SE}$ and $20.2 \pm 1.7$ g SE $(P<0.05)$ in emphysematous and control animals (Table II). Since in both groups tetanic tension correlated directly with cross-sectional area $(r=0.77$ : $P<0.01)$ and tetanic tension corrected for differences in cross-sectional area (i.e., tetanic tension $/ \mathrm{cm}^{2}$ ) was 


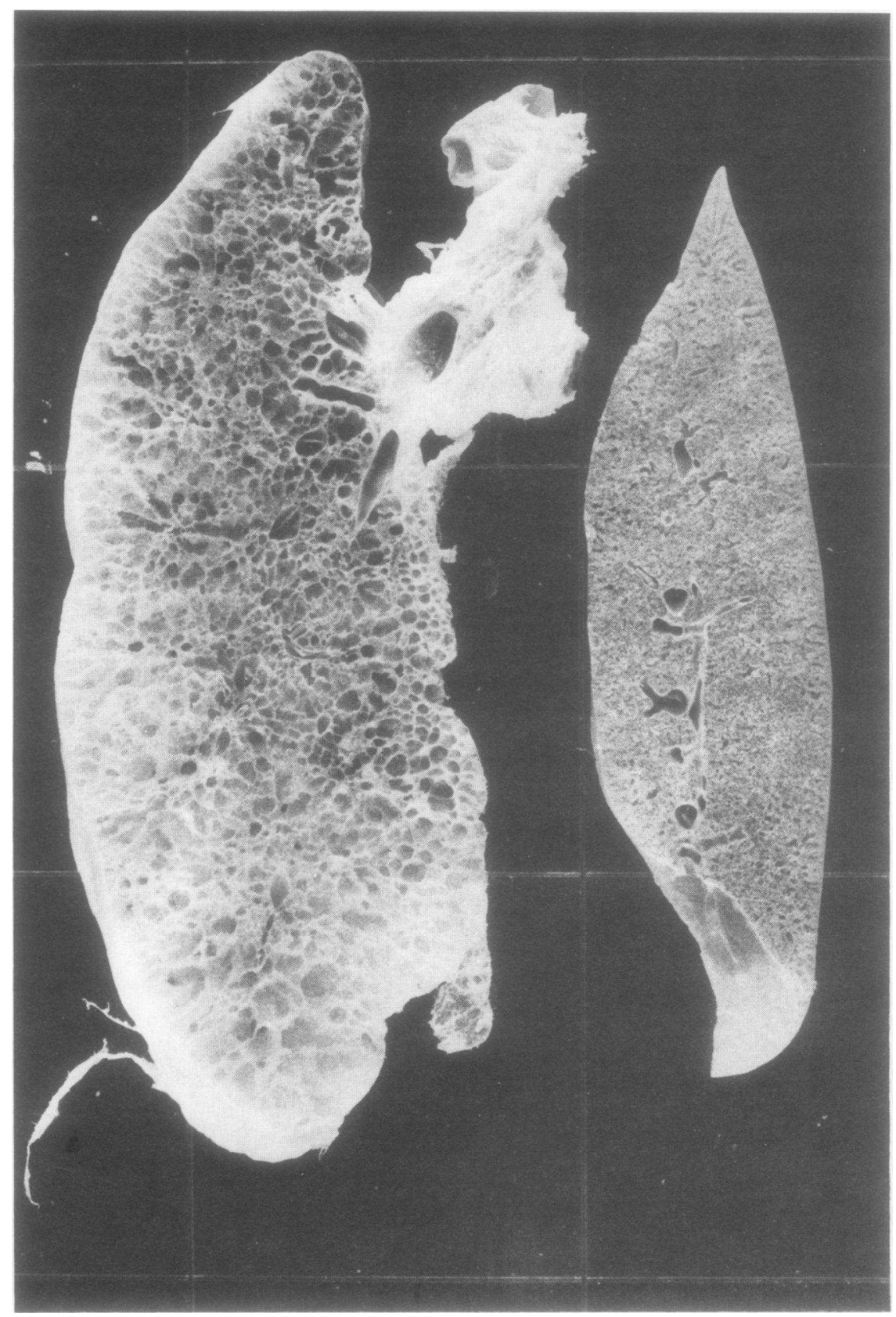

Figure 3 Coronal section of fixed inflated $\left(25 \mathrm{~cm} \mathrm{H}_{2} \mathrm{O}\right.$ pressure) lungs from an elastase-injected (left side) and age-matched control animal (right side). Lungs have been precipitated with barium sulfate to improve contrast. Note severe generalized panacinar emphysema and hyperinflation in the elastase-injected animal.

not significantly different in the two groups, the increased force generated by emphysematous animals appeared to be satisfactorily explained by increases in muscle cross-sectional area. The larger cross-sectional area in emphysematous animals ( $132 \%$ of control;
$P<0.01$ appeared in turn to be explained by increased muscle thickness ( $125 \%$ of control; $P<0.01$ ).

Relationship of diaphragmatic and soleus muscle tension to muscle fiber length. There was a systemic shift in the position of the muscle length tetanic tension 
TABLE II

Effect of Elastase-induced Emphysema on Diaphragmatic Tension

\begin{tabular}{lcccccc}
\hline & $\begin{array}{c}\text { Cross-sectional } \\
\text { area }\end{array}$ & Tetanic tension & Tetanic tension & $\begin{array}{c}\text { Twitch } \\
\text { tetanic tension }\end{array}$ & $\begin{array}{c}\text { Contraction } \\
\text { time }\end{array}$ & $\begin{array}{c}1 / 2 \text { Relaxation } \\
\text { time }\end{array}$ \\
\hline & $c m$ & $g$ & $g / c m^{2}$ & $\%$ & & $m s$ \\
$\begin{array}{c}\text { Control } \\
(\text { mean } \pm \text { SE) }\end{array}$ & $0.012 \pm 0.001$ & $20.2 \pm 1.7$ & $1854 \pm 136$ & $35 \pm 3$ & $69.6 \pm 1.8$ & $72.8 \pm 2.8$ \\
$\begin{array}{c}\text { Elastase } \\
(\text { mean } \pm \text { SE) }\end{array}$ & $0.016 \pm 0.001$ & $26.9 \pm 2.2$ & $1753 \pm 130$ & $28 \pm 3$ & $73.7 \pm 2.9$ & $64.3 \pm 2.5$ \\
& $P<0.01$ & $P<0.05$ & NS & NS & NS & $P<0.05$ \\
\hline
\end{tabular}

curve in emphysematous animals as compared with controls. In emphysematous animals, both the ascending and descending limbs of the length-tension curve occurred at shorter fiber lengths.

Active and passive diaphragm tension as a function of fiber length for the groups as a whole are shown in Fig. 4. In this figure, tetanic tension has been expressed as a percentage of the maximum value to allow length to be compared at the same level of active and passive tension. In emphysematous animals, active tension (top curve) was first generated and reached maximum values at shorter fiber lengths than in the controls. Note that for the groups as a whole, $\mathrm{L}_{0}$ in elastase-injected animals was $12.6 \pm 0.4 \mathrm{~mm}$ as compared with $14.4 \pm 0.3$ $\mathrm{mm}$ in control animals $(P<0.001)$. In addition, the range of muscle fiber lengths over which active tension occurred was compressed in the elastase-injected group $(3.4 \pm 0.2 \mathrm{~mm}$ vs. $4.3 \pm 0.2 \mathrm{~mm} ; P<0.01)$. Similarly, in emphysematous animals the passive length-tension curve (lower curve) was shifted to shorter lengths and increased more rapidly for a given increase in fiber length.

In contrast to the effects of elastase injection on the fiber length-tension curve of the diaphragm, there was no difference in the length-tension curves of the soleus muscle in elastase-injected and control animals indicating that alterations in diaphragm function were not a direct effect of elastase per se (Fig. 4).

Relationship of diaphragmatic tension to sarcomere length. Fig. 5 shows the fiber length-tension relationship of the diaphragm in individual control and elastase-injected animals whose fiber length curves (upper panel) occurred at widely different lengths. Note (upper panel) that in the elastase-injected animal there is a shift of both the active and passive lengthtension curve toward shorter muscle fiber lengths.

In the lower panel, active and passive tension are expressed as a function of sarcomere length. Note that in both animals active tension increased as sarcomere length increased and reached a maximum at a sarcomere length of $\sim 2.9 \mu \mathrm{m}$. Above this value active tension fell. Similarly, in both animals passive tension first developed at a sarcomere length of $\sim 2.9 \mu \mathrm{m}$ and increased similarly for any given increase in sarcomere length. In contrast to the differences in the position and range of the muscle fiber length-tension curve, therefore, both the active and passive tension curves of the two animals when expressed as a function of sarcomere length are superimposable. Similar results were obtained for the groups as a whole (Fig. 6). These data indicate that despite differences in the fiber length-tension relationship, the relationship between sarcomere length and diaphragmatic tension is the same in elastase-injected and control animals, suggesting that emphysema alters the relationship between sarcomere length and fiber length.

In emphysematous animals the number of sarcomeres in series calculated by laser diffraction (fiber length divided by mean sarcomere length) was reduced and appeared to explain the left shift of the fiber length-tension curve. Sarcomere number in emphysematous and control animals was $4,294 \pm 98 \mathrm{SE}$ and $4,830 \pm 100$, respectively (mean $88 \%$ of control; $P$ $<0.001$ ). Fig. 7 shows the relationship for each muscle strip in both groups between sarcomere number and a standardized point defining the position of the fiber length-tension curve, the fiber length at which active tension was maximum $\left(L_{0}\right)$. Note that for both emphysematous and control animals, a close, direct correlation existed between sarcomere number and $L_{0}$. The smaller the number of the sarcomeres present, the smaller was $\mathrm{L}_{0}(r=0.94 ; Y=0.0029 \mathrm{X}+0.001)$.

\section{DISCUSSION}

In the hamster, intratracheal injection of elastase produces an animal model of emphysema that closely resembles human panacinar emphysema both ultrastructurally and grossly (20). Functionally, the lungs of elastase-injected animals demonstrate changes similar to those observed in human emphysema. Lung compliance, functional residual capacity (FRC), residual volume (RV), and total lung capacity (TLC) are all increased (15-17). Hamsters with elastase-induced em- 

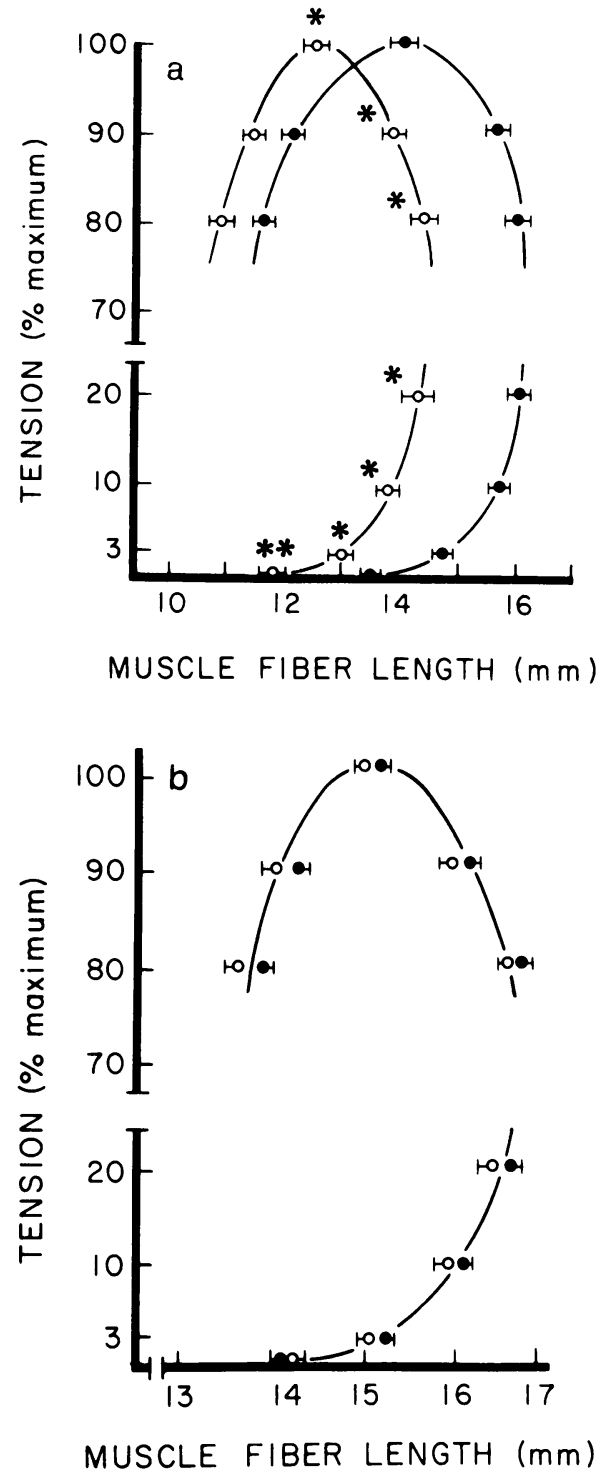

Figure 4 Diaphragm (a) and soleus (b) muscle fiber lengthtension curves in the entire group of control $(\bullet)$ and elastasetreated $(\mathrm{O})$ animals. Symbols represent mean value $\pm 1 \mathrm{SE}$. Top curves indicate active tension, bottom curves passive tension. Note the left shift of both the active and passive tension curves of the diaphragm in the emphysematous group. Statistical significance of differences in length at comparable points on the length-tension curve are shown by single $\left(^{\circ}\right)(P<0.01)$ and double asterisks $\left(^{\circ}\right)(P<0.05)$, re spectively. Soleus muscle fiber length-tension curves on the other hand, are the same in the two groups

physema also develop $\mathrm{CO}_{2}$ retention (18) and right ventricular hypertrophy (19), the major clinical complications of emphysema.

The time course of the tension wave form during a single twitch and the ratio of peak twitch to peak

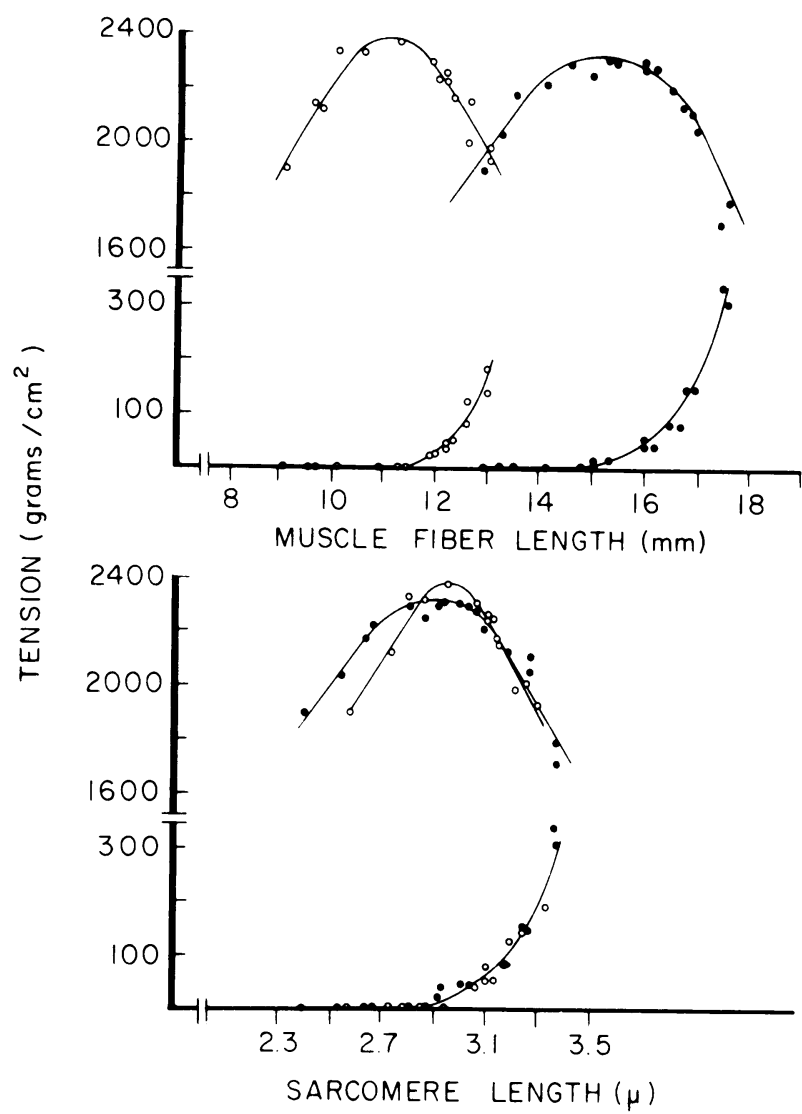

Figure 5 Diaphragm muscle fiber (top panel) and sarcomere (bottom panel) length-tension curves in single emphysematous $(O)$ and and control $(O)$ animals. Note that despite large differences in the active and passive tension curves plotted as a function of fiber length, the curves expressed as a function of sarcomere length are virtually superimposable.

tetanus are a reflection of the muscle fiber composition of skeletal muscle (32). Muscles composed primarily of slow twitch fibers develop and dissipate tension slowly (i.e., long contraction and relaxation time), and have a high twitch-tetanus ratio. The converse is true of muscles composed primarily of fast twitch fibers (32).

The lack of effect of elastase-induced emphysema on contraction time, twitch-tetanus ratio and tetanic tension $/ \mathrm{cm}^{2}$ suggests that large changes in the percentage of fast and slow twitch fibers have not occurred. The results are in agreement with most previous studies of whole heterogeneous limb skeletal muscle, which indicate that training regimens that increase either muscle strength or its endurance do not alter muscle fiber composition $(34,35)$.

Our study indicates that diaphragms from emphysematous animals, as a result of hypertrophy, gener- 


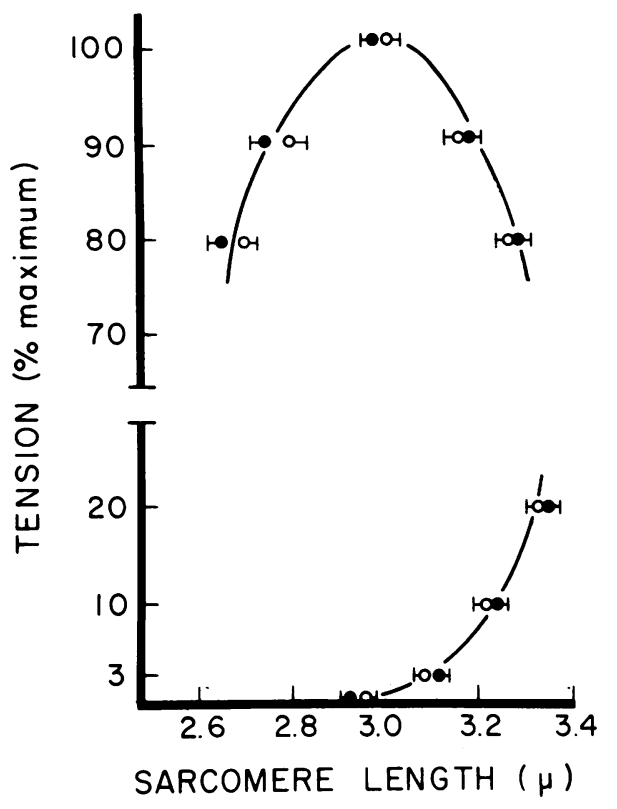

Figure 6 Sarcomere length-tension curve for diaphragm muscle strips in the entire group of elastase-injected $(O)$ and control $(\bullet)$ hamsters. Symbols represent mean $\pm 1 \mathrm{SE}$.

ated more force than controls. Of equal, or greater importance, however, diaphragms from emphysematous animals generated maximum tension at shorter fiber lengths.

The tension developed by a muscle depends on the rate and number of actin-myosin side-chain interactions (36). In the sliding filament model of Gordon, Huxley, and Julian $(21,36)$, the degree of overlap of the actin and myosin proteins, and hence the number of potential cross-links between the heavy meromyosin side chains of the myosin thick filament and the actin thin filament is a function of sarcomere length.

Acute increases in lung volume cause a reduction in muscle fiber and hence sarcomere length and move the diaphragm down its length-tension curve. In the absence of compensation for the chronic reduction in length, the length-tension curve of the muscle fiber and sarcomere would be the same in emphysematous and control animals, but would occupy different positions on the same curve. Hypertrophy, although not an ideal form of compensation for a reduction in length, produces a parallel upward shift of the lengthtension curve and, therefore, restores some of the force lost by changes in length.

This study indicates that another form of adaption for the persistent reduction in fiber length also occurs in experimentally induced emphysema. Leftward shift of the fiber length-tension curve allows the diaphragm to reestablish its mechanical advantage.

The observed shift in the diaphragm fiber length-

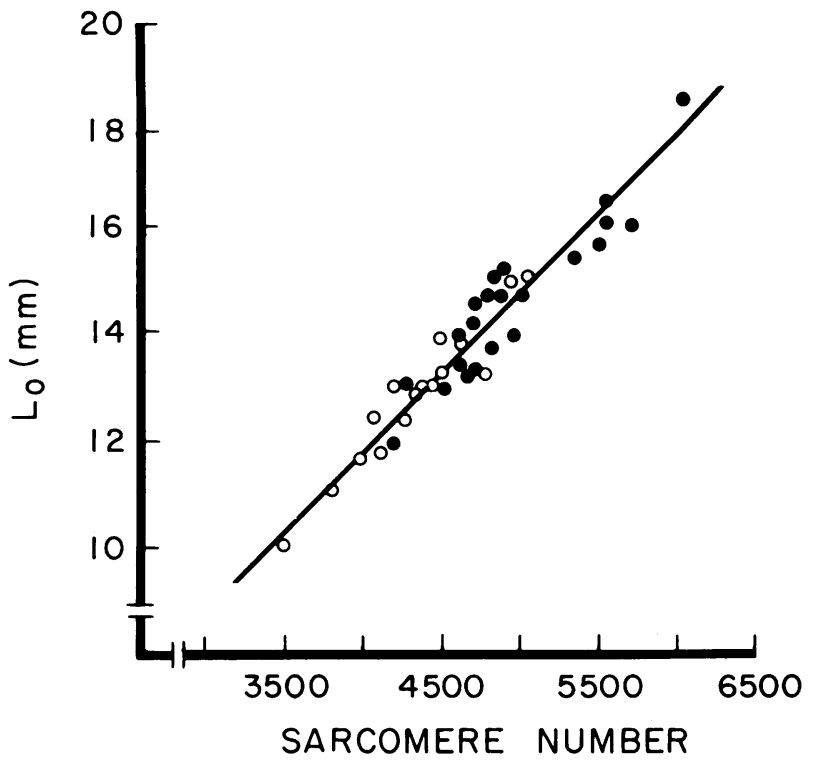

Figure 7 Relationship between $L_{0}$ (ordinate) and the number of sarcomeres in series (abscissa). Each point represents a single elastase $(O)$ or control $(O)$ muscle strip. Note that there is a direct relationship between the number of sarcomeres and the position of the length-tension curve represented by $\mathrm{L}_{0}^{\prime}(r=0.94 ; P<0.001)$.

tension curve in elastase-injected animals appears to be explained by the reduction in sarcomere number. The similarity of the sarcomere length-tension curves in the two groups and the close relationship between $\mathrm{L}_{0}$ and sarcomere number provide strong support for this possibility. A reduction in sarcomere number would cause a left shift of the fiber length-tension curve by altering the ratio of sarcomere to fiber length. With a reduction in sarcomere number, the optimal sarcomere length would, of necessity, occur at a shorter fiber length.

Several other less likely mechanisms that could explain the shift in the muscle fiber length-tension curve are theoretically possible. Sarcomere length is determined by the degree of stretch on its $\mathrm{Z}$ disc boundaries. A decrease in the compliance of the series elastic element in diaphragmatic muscle might result in a longer sarcomere length for a given muscle length. The fact that the change in passive tension produced by a given change in muscle fiber length was greater in emphysematous animals is consistent with this possibility or with a reduction in the number of sarcomeres in series. The observed reduction in sarcomere number excludes changes in series elasticity as the sole explanation for the length-tension curve shift. Furthermore, similarity of the sarcomere number- $\mathrm{L}_{0}$ curve in emphysematous and control animals would appear to rule out this possibility entirely. 
Finally, it seems possible that a change in the structure or orientation of the actin-myosin contractile proteins, which would reduce the sarcomere length at which tension is maximal, would also shift the fiber length-tension curve to the left. This possibility would appear to be excluded since sarcomere length-tension curves in the two groups are virtually identical.

Plasticity in sarcomere number in chronically stretched or shortened muscles has been demonstrated previously (37-39). In cat limb muscles immobilized at lengths above or below the resting value by casting, the number of sarcomeres in series was reduced in the shortened muscle and increased in the stretched muscle (38). Alterations in sarcomere number are accomplished rapidly (within a 1-2-wk period). The signal that causes the muscle to alter the number of sarcomeres in series remains unclear. However, since these adaptations occur in denervated muscle (37) and are not dependent on the magnitude of passive or active muscle tension (39), muscle length per se appears to be the critical factor.

This study was performed in animals 18 mo after elastase administration, and does not provide data on the time course of the adaptive responses in the diaphragm. However, studies by Farkas and Roussos (40) in animals studied 6 mo after elastase administration, indicate that similar shifts in the fiber length-tension curve are present. Leftward shifts in the muscle fiber and length-tension curve and muscle fiber hypertrophy have also been observed by us in emphysematous animals examined 3 mo after elastase. These observations suggest that the adaptive changes in the diaphragm take place well before $18 \mathrm{mo}$.

The ratio of fiber length measured in situ to $\mathrm{L}_{0}$ was $97 \pm 3 \%$ in the emphysematous and $106 \pm 2 \%$ in control animals. These ratios indicate that in both the elastasetreated and control animals the fiber lengths in situ with the chest closed fall close to the peak of the length-tension curves. We recognize, however, that muscle fiber length measured postmortem with the abdomen open may differ substantially from the length existing in vivo at FRC. (For example, if tonic activation of the diaphragm occurs throughout the respiratory cycle in the hamster as it does in human newborns, diaphragm fiber length would tend to be shorter in vivo [40].) To the extent, however, that the fiber length measurements made in the present study reflect muscle fiber length in vivo at FRC, the length adaptation resulting from a reduction in the number of sarcomeres was almost perfect in the emphysematous animals.

The zone of apposition that exists between the diaphragm and the lowermost ribs appears to allow a sizable increase in lung volume without change in the shape of the diaphragm (41). Very large increases in lung volume produced by emphysema, however, may alter diaphragmatic configuration $(2-5,7)$ and may have in the present study increased the effective radius of curvature of the diaphragm. If this occurred, length compensation that just restored the tension-generating ability of the diaphragm to normal would not be enough to maintain transdiaphragmatic pressure at a normal level. Rather, from the LaPlace equation ( $P$ $=2 \mathrm{~T} / \mathrm{r}$ ) increased tension would be required to maintain a given level of transdiaphragmatic pressure $(8$, $9,14)$. Increased tension would require increased motor activity. Chronic increases in motor activity increase the myofibrillar content and fiber cross-sectional area of limb skeletal muscle (35) and may, in part, explain hypertrophy of the diaphragm in elastase-induced emphysema.

Restructuring of the diaphragm in the elastase-induced emphysema may explain some of the observations on the appearance of the diaphragm at autopsy in patients with emphysema. While studies of the dimensions of the human diaphragm in patients with chronic obstructive lung disease are conflicting $(3,43-$ 48), studies by Butler (43) and Steel and Heard (46) indicate that the area of the muscular portion of the diaphragm is reduced. Butler, in fact, showed that the reduction in area correlated directly with the extent of emphysema present. Isikawa and Hayes (44) in a smaller series, on the other hand, found no difference in area in patients with chronic obstructive lung disease. Because the diaphragm is approximately ovoid, a reduction in muscle surface area may be explained by a reduction in muscle fiber length and sarcomere number (48).

Studies of diaphragm thickness are also not in agreement. Isikawa and Hayes (44) and Scott and Hoy (45) report increases in diaphragm thickness and muscle fiber cross-sectional area. On the other hand, Steele and Heard (46) report decreases in diaphragm thickness in patients with chronic obstructive lung disease. The differing results obtained in the human studies may be explained in part by the confounding effects of differences in body habitus or nutritional status, known to affect the dimensions of the diaphragm (49). Nontheless, the reduced diaphragm surface area and increased muscle thickness seen in some autopsy series may be the gross morphologic representation of the adaptations observed in the present study. In patients with chronic obstructive lung disease, changes in sarcomere number in diaphragmatic muscle may compensate, in part, for chronically maintained hyperinflation of the thorax, while diaphragmatic hypertrophy may represent a response to alterations in respiratory load and/or changes in muscle configuration (LaPlace relationship). 


\section{ACKNOWLEDGMENTS}

This work was supported, in part, by program project grant HL-25830 (National Heart, Lung, and Blood Institute) and Pulmonary Academic Award HL-00450 (Dr. Kelsen).

\section{REFERENCES}

1. Cherniack, R. M. 1959. The oxygen consumption and efficiency of the respiratory muscles in health and emphysema. J. Clin. Invest. 38: 494-499.

2. Sharp, J. T., J. Danon, W. S. Druz, N. B. Goldberg, H. Fishman, and W. Machnach. 1974. Respiratory muscle function in patients with chronic obstructive pulmonary disease; its relationship to disability and to respiratory therapy. Am. Rev. Respir. Dis. 110: 154-167.

3. Rochester, D. F., N. S. Arora, N. M. T. Braun, and S. K. Goldberg. 1979. The respiratory muscles in chronic obstructive pulmonary disease (COPD). Bull. Eur. Physiopathol. Respir. 15: 951-975.

4. Derenne, J. P., P. T. Macklem, and C. L. Roussos. 1978. The respiratory muscles: mechanics, control, and pathophysiology. Parts I, II, and III. Am. Rev. Respir. Dis. 118: 115-133; 373-390; 581-601.

5. Rochester, D. F., and N. M. T. Braun. 1978. The respiratory muscles. Basics $R D$. 6: $1-6$.

6. Sharp, J. R., P. VanLith, C. Voj Nuchprayoon, R. Briney, and $\mathrm{F}$. N. Johnson. 1968. The thorax in chronic obstructive lung disease. Am. J. Med. 44: 39-46.

7. Rochester, D. F., N. M. T. Braun, and N. S. Arora. 1978. Respiratory muscle strength in chronic obstructive pulmonary disease. Am. Rev. Respir. Dis. 117: 151-154.

8. Marshall, R. 1962. Relationships between stimulus and work of breathing at different lung volumes. J. Appl. Physiol. 17(6): 917-921.

9. Pengelly, L. D., A. M. Aldorsa, and J. Milic-Emili. 1971. Mechanics of the canine diaphragm. J. Appl. Physiol. 30(6): 797-805.

10. Evanich, M. J., M. J. Franco, and R. V. Lourenco. 1973. Force output of the diaphragm as a function of phrenic nerve firing rate and lung volume. J. Appl. Physiol. 35(2): 208-212

11. Kim, M. J., W. S. Drus, J. Danon, W. Machnach, and J. T. Sharp. 1976. Mechanics of the canine diaphragm. J. Appl. Physiol. 41: 369-382.

12. Sharp, J. T., N. S. Goldberg, W. S. Druz, H. C. Fishman, and J. Danon. 1977. Thoraco-abdominal motion in chronic obstructive pulmonary disease. Am. Rev. Respir. Dis. 115: 47-56.

13. Byrd, R. B., and R. E. Hyatt. 1968. Maximal respiratory pressures in chronic obstructive lung disease. Am. Rev. Respir. Dis. 98: 848-856.

14. Grassino, A., M. D. Goldman, J. Mead, and T. A. Sears. 1978. Mechanics of the human diaphragm during voluntary contraction: statics. J. Appl. Physiol. Respir. Environ. Exercise Physiol. 44: 829-839.

15. Karlinsky, J. B., and G. L. Snider. 1978. State of the art: animal models of emphysema. Am. Rev. Respir. Dis. 117: 1109-1133.

16. Snider, G. L., C. B. Sherter, K. W. Koo, J. B. Karlinsky, J. A. Jayes, and C. Franzblau. 1977. Respiratory mechanics in hamsters following treatment with endotracheal elastase or collagenase. J. Appl. Physiol. Respir. Environ. Exercise Physiol. 42: 206-215.

17. Snider, G. L., and C. B. Sherter. 1977. A one-year study of the evolution of elastase-induced emphysema in hamsters. J. Appl. Physiol. 43(4): 721-729.
18. Lucey, E. C., J. J. O’Brien, W. Perevira, and G. L. Snider. 1980. Arterial blood gas values in emphysematous hamsters. Am. Rev. Respir. Dis. 121: 83-89.

19. Cooper, B. S., and C. Kuhn. 1978. Cor pulmonale in elastase-induced emphysema. Am. Rev. Respir. Dis. 117: $324 a$.

20. Kohn, C., and F. Tavassoli. 1976. The scanning electron microscopy of elastase-induced emphysema: a comparison with emphysema in man. Lab Invest. 34: 2-9.

21. Gordon, A. M., A. F. Huxley, and F. J. Julian. 1966. Tension development in highly stretched vertebrate muscle fibers. J. Physiol. 184: 143-169.

22. Hill, D. K. 1968. Tension due to interaction between the sliding filaments in resting striated muscle. The effect of stimulation. J. Physiol. 199: 143-169.

23. Zite-Ferenczy, F., and R. Rüdel. 1978. A diffractometer using a lateral effect photodiode for the rapid determination of sarcomere length changes in cross-striated muscle. Pfluegers Archiv. 374: 97-100.

24. Bartels, E. M., J. M. Skydsgaard, and O. Sten-Knudsen. 1979. The time course of the latency relaxation as a function of the sarcomere length in frog and mammalian muscle. Acta Physiol. Scand. 106: 129-137.

25. Fujime, S. 1975. Optical diffraction study of muscle fibers. Biochim. Biophys. Acta. 379: 227-238.

26. TerKeurs, H. E. D. J., T. Iwzaumi, and G. H. Plllack. 1978. The sarcomere length-tension relation in skeletal muscle. J. Gen. Physiol. 72: 565-592.

27. Delay, M. J., N. Ishide, R. D. Jackson, G. F. Pollack, and R. Tirosh. 1981. Stepwise sarcomere shortening: analysis by high speed cinemicrography. Science (Wash., DC). 213: 1523 ; 1525.

28. Cleworth, D. R., and K. A. P. Erdman. 1972. Changes in sarcomere length during isometric tension development in frog skeletal muscle. J. Physiol. (Lond.). 227: $1-17$.

29. Kelsen, S. G., and M. Nochomovitz. 1982. Fatigue of the mammalian diaphragm in vitro. J. Appl. Physiol. Respir. Environ. Exercise Physiol. 53: 440-447.

30. Wittmann, T. A., and S. G. Kelsen. 1982. Diaphragmatic muscle force in normal hamsters: the effect of caffeine. Am. Rev. Respir. Dis. 126: 499-504.

31. Robbins, N., A. Olek, S. S. Kelly, P. Takach, and M. Christopher. 1980. Quantitative study of motor endplates in muscle fibers disassociated by a simple procedure. Proc. R. Soc. Lond. B Biol. Sci. 209: 555-562.

32. Close, R. E. 1972. The dynamic properties of mammalian skeletal muscles. Physiol. Rev. 52: 129-197.

33. Dubowitz, V., and M. H. Brooke. 1973. Muscle Biopsy: A Modern Approach. W. B. Saunders Company, London.

34. Holloszy, J. O., and F. W. Booth. 1976. Biochemical adaptations to endurance exercises in muscle. Annu. Rev. Physiol. 38: 273-291.

35. Jolesz, F., and F. A. Reter. 1981. Development, innervation, and activity pattern-induced changes in skeletal muscle. Annu. Rev. Physiol. 43: 531-552.

36. Huxley, A. F. 1974. Muscular contraction. J. Physiol. (Lond). 243: 1-43.

37. Goldspink, G., C. Tabary, J. C. Tabary, G. Tardiou, and C. Tardiou. 1974. Effect of denervation on the adaptation of sarcomere numbei and muscle extensibility to the functional length of the muscle. J. Physiol. (Lond.). 236: 733: 742 .

38. Tabary, J. C., C. Tabary, C. Tardiou, G. Tardiou, and G. Goldspink. 1976. Physiological and structural changes in the cat's soleus muscle due to immobilization at dif- 
ferent lengths by plaster casts. J. Physiol. (Lond.). 224: 231-244.

39. de LaTour, E., E. Huet, J. C. Tabary, C. Tabary, and C. Tardiou. 1979. The respective roles of muscle length and muscle tension in sarcomere number adaptation of guinea pig soleus muscle. J. Physiol. (Paris). 75: 589659.

40. Farkas, G. A., and C. Roussos. 1981. Diaphragmatic length-tension curve at normal and emphysematous hamsters. Physiologist. 24: 92.

41. Muller, N., G. Volgyesi, L. Becker, M. H. Bryan, and A. C. Bryan. 1979. Diaphragmatic muscle tone. J. Appl. Physiol. Respir. Environ. Exercise Physiol. 47: 279-284.

42. Mead, J. 1979. Functional significance of the area of apposition of diaphragm to rib cage. Am. Rev. Respir. Dis. 119(Suppl.): 31-32.

43. Butler, C. 1976. Diaphragmatic changes in emphysema. Am. Rev. Respir. Dis. 114: 155-159.
44. Ishikawa, S., and J. A. Hayes. 1973. Functional morphometry of the diaphragm in patients with chronic obstructive lung disease. Am. Rev. Respir. Dis. 108: 135138.

45. Scott, K. W. M., and J. Hoy. 1976. The cross-sectional area of diaphragmatic muscle fibers in emphysema, measured by an automated image analysis system. $J$. Pathol. 110: 121-128.

46. Steele, R. H., and B. E. Heard. 1973. Size of the diaphragm in chronic bronchitis. Thorax. 28: 55-60.

47. Thurlbeck, W. M. 1978. Diaphragm and body weight in emphysema. Thorax. 33: 483-487.

48. Rochester, D. F. 1980. Zwerchfell-Mechanik und Energetik bei chronischem obstructiven Lungenkrankheiten. Atemswegs Lungenkr. 6: 117-120.

49. Arora, N., and D. F. Rochester. 1982. Effect of body weight and muscularity on diaphragm muscle mass, thickness, and area. J. Appl. Physiol. Respir. Environ. Exercise Physiol. 52: 64-70. 